\title{
AVALIAÇÃO DO DESEMPENHO DA EXTRAÇÃO LÍQUIDO- LÍQUIDO NA DESACIDIFICAÇÃO DO ÓLEO DE COCO PARA PRODUÇÃO DE BIODIESEL
}

\author{
K. E. N. TOMISHIMA ${ }^{1}$, L. F. TEIXEIRA ${ }^{1}$, T. R. CARVALHO ${ }^{1}$ e H. F. De CASTRO ${ }^{1}$ \\ ${ }^{1}$ Escola de Engenharia de Lorena-USP(EEL-USP), Departamento de Engenharia Química \\ E-mail para contato: larissa@ dequi.eel.usp.br
}

\begin{abstract}
RESUMO - O presente trabalho teve como objetivo estudar a desacidificação do óleo de coco por meio da extração líquido-líquido para a obtenção de matéria-prima adequada para a produção de biodiesel. Foram testadas três amostras de óleo com diferentes níveis de acidez (Amostra I - 19,00; Amostra II - 13,68 e Amostra III - 0,46 $\mathrm{mg} \mathrm{KOH} / \mathrm{g}$ amostra), investigando-se a influência da proporção mássica de óleo:solvente (etanol anidro) $(1: 1 ; 1: 1,5 ; 1: 2)$ e da concentração de água no solvente $(2 \%, 4 \%, 6 \%)$ no processo de extração. O desempenho do método foi avaliado a partir de um planejamento experimental $\left(2^{2}\right.$ de face centrada), visando-se maximizar a recuperação mássica de óleo neutro e a remoção de ácidos graxos livres da matériaprima lipídica em duplo estágio. Os resultados demonstraram elevados valores de recuperação mássica de óleo neutro $(72,41 ; 84,59$ e 79,11\%) e redução de ácidos graxos livres (71,58; 62,81 e 95,86\%), respectivamente para as amostras de óleo I, II e III, comprovando a eficiência da técnica utilizada.
\end{abstract}

\section{INTRODUÇÃO}

A busca por matérias-primas alternativas para a produção de biodiesel, como por exemplo, óleos vegetais de baixo impacto na cadeia alimentícia, está associada ao custo final do produto, que deverá apresentar competitividade em relação ao diesel mineral. Entretanto, um elevado nível de acidez no óleo bruto interfere negativamente no rendimento do processo, uma vez que a utilização de catalisadores básicos pelo método convencional (transesterificação alcalina) resulta na formação de sabões. Isso dificulta a purificação do produto, tornando imprescindível a redução ou remoção desses ácidos graxos livres oriundos da matéria-prima lipídica (Atadashi et al., 2012).

Os óleos comercializados são, em geral, produzidos a partir de refino químico ou físico. O refino químico, o qual emprega geralmente o hidróxido de sódio, como agente químico, ao óleo degomado, não é recomendado para óleos com elevado teor de ácidos graxos livres por proporcionar perdas consideráveis de óleo neutro devido à reação de hidrólise em meio básico e da captura de óleo neutro pela borra resultante, que pode ser composta de até $50 \%$ em massa de lipídeos (Bhosle; Sibramanian, 2005). Por outro lado, o refino físico, como por exemplo, a vaporização dos ácidos graxos livres, requer temperaturas muito elevadas e pressões reduzidas para possibilitar a separação dos ácidos graxos dos triglicerídeos por arraste mecânico durante a volatilização, causando prejuízos a qualidade do produto final (Ceriani; Meirelles, 2006). 
A desacidificação do óleo bruto por extração liquido-liquido (ELL), também denominada como extração líquida ou extração por solvente, tem despertado interesse devido às vantagens que apresenta em relação aos refinos físico e químico. Como a ELL é conduzida a temperaturas próximas a do ambiente, reduz o consumo energético e submete o óleo a tratamentos mais brandos, permitindo a preservação dos compostos nutracêuticos. Adicionalmente, a ELL tem a vantagem de evitar a produção de poluentes e reduzir as perdas de óleo neutro (Rezende-Ribeiro, 2009).

Nesse contexto, o presente trabalho tem como objetivo estudar o processo de desacidificação de óleo vegetal por meio da operação unitária de extração líquido-líquido (ELL), como rota alternativa ao modo convencional. Para esta finalidade, foi selecionado o óleo de coco, por apresentar baixo impacto na cadeia alimentícia e possuir uma composição predominantemente láurica, favorável para a reação de transesterificação, empregando água e etanol como solvente, objetivando-se ampliar as opções de matérias-primas lipídicas para a produção de biodiesel.

\section{MATERIAIS E MÉTODOS}

\subsection{Materiais de Partida}

A matéria-prima lipídica utilizada foi o óleo de coco, adquirido comercialmente no Mercado Municipal de Fortaleza, apresentando diferentes níveis de ácidos graxos livres $(19,00,13,68$ e 0,46 $\mathrm{mg}_{\mathrm{KOH}} / \mathrm{g}_{\mathrm{amostra}}$ ) e composição aproximada em ácidos graxos de: 7,1\% Octanóico, 7,3\% Decanóico, 54,1\% Láurico, 17,4\% Mirístico, 6,1\% Palmítico, 1,6\% Esteárico, 5,1\% Oléico e 1,3\% Linoléico e massa molecular de 682,23 g.mol ${ }^{-1}$. Como solvente utilizou-se água destilada e álcool etílico absoluto (99\%, Cromoline).

\subsection{Desacidificação do Óleo de Coco por Extração Líquido-Líquido}

As extrações foram realizadas em duplo estágio, sendo que cada estágio foi realizado em béquer de $100 \mathrm{~mL}$ contendo óleo de coco e uma mistura de álcool etílico anidro e água em diferentes proporções mássicas de óleo/solvente $(1: 1 ; 1: 1,5$ e 1:2) sob temperatura ambiente. Também foi estudada a influência da concentração de água presente na mistura $(2,4$ e $6 \%)$. $\mathrm{O}$ sistema foi agitado por 15 minutos sobre uma placa de agitação magnética, para gerar a maior área de superfície e deslocar os ácidos graxos livres do óleo para o solvente. Posteriormente, a mistura foi centrifugada por 15 minutos a $3500 \mathrm{rpm}$ (Modelo 206-BL, Excelsa II - Fanem) e deixada em repouso para a separação das fases hidrofílica e hidrofóbica (particionamento). A fase rica em óleo foi separada, pesada e utilizada para análises posteriores de recuperação mássica e redução de acidez, sendo a fase alcoólica descartada.

\subsection{Planejamento de Experimento}

A influência da proporção mássica de óleo: solvente $(1: 1$ - 1:2) e concentração de água no solvente $(2-6 \%)$ na extração líquido-líquido de ácidos graxos livres em amostras de óleo de coco foi avaliada segundo um planejamento fatorial $2^{2}$ de face centrada. Ressalta-se que as amostras foram refinadas de acordo com o planejamento fatorial proposto (único estágio) e novamente tratadas sob as mesmas condições (duplo estágio). A análise estatística dos resultados foi realizada utilizando-se o programa STATISTICA 8.0 e Design Expert 6.0, considerando como variáveis 
respostas a recuperação mássica de óleo refinado (\%) e a remoção de ácidos graxos livres da matéria-prima lipídica (\%).

\subsection{Caracterização do Óleo de Coco}

A caracterização do óleo de coco foi baseada nos índices de acidez, peróxido, iodo e saponificação adotando normas estabelecidas pela AOCS (2004).

\section{RESULTADOS E DISCUSSÃO}

\subsection{Propriedades Físico-Químicas das Amostras do Óleo de Coco}

A qualidade da matéria-prima lipídica utilizada na reação de transesterificação é de fundamental importância, tendo em vista que venenos ou inibidores catalíticos podem reduzir o rendimento da reação. As amostras de óleo de coco foram caracterizadas quanto aos teores de interesse para controle de qualidade, incluindo índices de acidez, iodo, peróxido e saponificação. Os dados obtidos estão apresentados na Tabela 1.

Tabela 1 - Propriedades das amostras de óleo de coco utilizadas

\begin{tabular}{|c|c|c|c|}
\hline Índice & Amostra I & Amostra II & Amostra III \\
\hline Acidez (mg KOH/g óleo) & 19,05 & 13,68 & 0,46 \\
\hline Peróxido (mEq/kg) & 3,96 & 11,25 & 0,77 \\
\hline Iodo (g I $/ \mathbf{1 0 0 g ~ d e ~ o ́ l e o ) ~}$ & 12,04 & 18,47 & 6,62 \\
\hline Saponificação (mg KOH/g óleo) & 264 & 245 & 241 \\
\hline
\end{tabular}

A acidez livre de óleos e gorduras é proveniente da hidrólise parcial dos glicerídeos, sendo sua medida muito importante, pois revela a qualidade da matéria-prima, relacionado com o processamento e, principalmente, com as condições de conservação do produto (Ribeiro; Seravalli, 2007). A elevada acidez apresentada pelas Amostras I e II pode influenciar negativamente no rendimento de transesterificação, principalmente quando a catálise for alcalina, sendo necessário um pré-tratamento antes da sua aplicação. Outra propriedade importante dessas matérias-primas é a estabilidade oxidativa, diretamente relacionada à temperatura de uso e ao tempo de estocagem do produto (Moustafa; Staufeer, 1997). Dentre as amostras testadas, apenas a Amostra II não atendeu ao limite estabelecido pela Anvisa que é $10 \mathrm{meq} / \mathrm{kg}$ (Anvisa, 2013), o que também poderia afetar a eficácia de uma catálise enzimática, na qual valores superiores a 5 meq/Kg não são recomendados (Ibrahim et al., 2007).

Tanto os índices de iodo como o de saponificação estão relacionados com os tipos de ácidos graxos presentes na matéria-prima lipídica, sendo o índice de saponificação útil para verificação da massa molecular média de um óleo e da adulteração por outros óleos, enquanto que o índice de iodo mede a quantidade de insaturação presente no lipídio. De acordo com a Tabela 1, os valores obtidos para as amostradas testadas ficaram dentro de uma faixa esperada, visto que são provenientes da mesma fonte vegetal (Cocus nucifera).

Embora a amostra III tenha apresentado baixos valores de acidez e peróxido, esta também foi avaliada, visando verificar a eficácia da técnica de extração liquido-liquido na remoção de ácidos graxos livres mesmo para matérias-primas com baixos níveis de acidez. 


\subsection{Otimização das Condições de ELL por Planejamento Fatorial em Duplo Estágio}

Visando otimizar as condições da ELL, foi proposto um planejamento fatorial composto de face centrada $2^{2}$, definindo como variáveis independentes: a proporção mássica de óleo:solvente $\left(\mathrm{X}_{1}\right)$ e a concentração de água no solvente $\left(\mathrm{X}_{2}\right)$. Como variáveis respostas foram consideradas a porcentagem de recuperação mássica de óleo refinado $\left(\mathrm{R}_{1}\right)$ e a porcentagem de remoção de ácidos graxos livres na matéria-prima lipídica $\left(\mathrm{R}_{2}\right)$. A matriz experimental, bem como os resultados obtidos para as amostras de óleo I, II e III são mostrados nas Tabelas 2, 3 e 4, respectivamente. Observa-se que a EEL se mostrou eficiente para todas as amostras testadas, mesmo apresentando diferentes níveis de acidez. A partir da análise estatística foi possível gerar os gráficos de Pareto (Figuras 1, 2 e 3) que mostram os efeitos padronizados ( $t$ calculado em relação a $t$ tabelado, com $95 \%$ de confiança) relacionados às varáveis respostas para as amostras de óleo de coco após o tratamento em duplo estágio.

Tabela 2 - Resultados obtidos para a amostra I de acordo com o planejamento fatorial de face centrada $2^{2}$.

\begin{tabular}{ccccccccc}
\hline & \multicolumn{3}{c}{ Variável } & \multicolumn{2}{c}{ Variável } & \multicolumn{2}{c}{$\mathbf{1}^{\mathbf{0}}$ Estágio } & \multicolumn{2}{c}{$\mathbf{2}^{\mathbf{0}}$ Estágio } \\
Ensaio & $\mathbf{X}_{\mathbf{1}}$ & $\mathbf{X}_{\mathbf{2}}$ & $\mathbf{X}_{\mathbf{1}}$ & $\mathbf{X}_{\mathbf{2}}$ & & & & \\
& & & & & $\mathbf{R}_{\mathbf{1}}(\boldsymbol{\%})$ & $\mathbf{R}_{\mathbf{2}}(\boldsymbol{\%})$ & $\mathbf{R}_{\mathbf{1}}(\boldsymbol{\%})$ & $\mathbf{R}_{\mathbf{2}}(\boldsymbol{\%})$ \\
\hline 1 & -1 & -1 & $1: 1$ & 2 & 100,00 & 44,85 & 58,11 & 55,91 \\
2 & -1 & +1 & $1: 1$ & 6 & 99,48 & 48,39 & 80,69 & 51,23 \\
3 & +1 & -1 & $1: 2$ & 2 & 65,89 & 68,69 & 57,38 & 57,79 \\
4 & +1 & +1 & $1: 2$ & 6 & 88,17 & 67,26 & 70,76 & 69,84 \\
5 & 0 & 0 & $1: 1,5$ & 4 & 89,77 & 60,94 & 71,98 & 64,88 \\
6 & 0 & 0 & $1: 1,5$ & 4 & 91,05 & 60,93 & 69,55 & 65,71 \\
7 & 0 & 0 & $1: 1,5$ & 4 & 91,32 & 61,16 & 69,95 & 66,75 \\
8 & -1 & 0 & $1: 1$ & 4 & 100,00 & 49,51 & 73,69 & 41,46 \\
9 & +1 & 0 & $1: 2$ & 4 & 81,94 & 68,77 & 70,48 & 73,15 \\
10 & 0 & -1 & $1: 1,5$ & 2 & 79,60 & 59,91 & 53,70 & 65,31 \\
11 & 0 & +1 & $1: 1,5$ & 6 & 95,85 & 59,61 & 75,37 & 64,27 \\
\hline
\end{tabular}

Tabela 3 - Resultados obtidos para a amostra II de acordo com o planejamento fatorial de face centrada $2^{2}$.

\begin{tabular}{ccccccccc}
\hline & \multicolumn{3}{c}{ Variável } & \multicolumn{2}{c}{ Variável } & \multicolumn{2}{c}{$\mathbf{1}^{\mathbf{0}}$ Estágio } & \multicolumn{2}{c}{$\mathbf{2}^{\mathbf{0}}$ Estágio } \\
Codificada & \multicolumn{2}{c}{ Real } & & & & \\
& & $\mathbf{X}_{\mathbf{1}}$ & $\mathbf{X}_{\mathbf{2}}$ & $\mathbf{X}_{\mathbf{1}}$ & $\mathbf{X}_{\mathbf{2}}$ & & & \\
& & & & & $\mathbf{R}_{\mathbf{1}}(\boldsymbol{\%})$ & $\mathbf{R}_{\mathbf{2}}(\boldsymbol{\%})$ & $\mathbf{R}_{\mathbf{1}}(\boldsymbol{\%})$ & $\mathbf{R}_{\mathbf{2}}(\boldsymbol{\%})$ \\
\hline 1 & -1 & -1 & $1: 1$ & 2 & 100,00 & 54,00 & 65,96 & 54,92 \\
2 & -1 & +1 & $1: 1$ & 6 & 98,43 & 47,18 & 97,77 & 45,69 \\
3 & +1 & -1 & $1: 2$ & 2 & 76,13 & 66,40 & 77,69 & 68,51 \\
4 & +1 & +1 & $1: 2$ & 6 & 90,14 & 67,72 & 78,06 & 68,15 \\
5 & 0 & 0 & $1: 1,5$ & 4 & 94,87 & 62,20 & 82,21 & 63,91 \\
6 & 0 & 0 & $1: 1,5$ & 4 & 94,18 & 62,50 & 80,20 & 63,41 \\
7 & 0 & 0 & $1: 1,5$ & 4 & 93,53 & 62,37 & 75,84 & 62,58 \\
8 & -1 & 0 & $1: 1$ & 4 & 100,00 & 50,27 & 96,70 & 47,51 \\
9 & +1 & 0 & $1: 2$ & 4 & 87,89 & 68,11 & 78,50 & 67,70 \\
10 & 0 & -1 & $1: 1,5$ & 2 & 89,60 & 58,63 & 70,92 & 66,19 \\
11 & 0 & +1 & $1: 1,5$ & 6 & 96,14 & 60,43 & 92,31 & 59,15 \\
\hline
\end{tabular}


Tabela 4 - Resultados obtidos para a amostra III de acordo com o planejamento fatorial de face centrada $2^{2}$.

\begin{tabular}{ccccccccc}
\hline & \multicolumn{3}{c}{ Variável } & \multicolumn{2}{c}{ Variável } & \multicolumn{2}{c}{$\mathbf{1}^{\mathbf{0}}$ Estágio } & \multicolumn{2}{c}{$\mathbf{2}^{\mathbf{o}}$ Estágio } \\
Codificada & \multicolumn{2}{c}{ Real } & & & & \\
& & & & & $\mathbf{R}_{\mathbf{1}}(\boldsymbol{\%})$ & $\mathbf{R}_{\mathbf{2}}(\boldsymbol{\%})$ & $\mathbf{R}_{\mathbf{1}}(\boldsymbol{\%})$ & $\mathbf{R}_{\mathbf{2}}(\boldsymbol{\%})$ \\
\hline 1 & -1 & -1 & $1: 1$ & 2 & 100,00 & 43,40 & 73,62 & 57,97 \\
2 & -1 & +1 & $1: 1$ & 6 & 100,00 & 43,49 & 90,16 & 52,52 \\
3 & +1 & -1 & $1: 2$ & 2 & 88,27 & 64,04 & 48,96 & 79,29 \\
4 & +1 & +1 & $1: 2$ & 6 & 95,58 & 66,99 & 80,25 & 87,44 \\
5 & 0 & 0 & $1: 1,5$ & 4 & 100,00 & 58,45 & 79,22 & 78,81 \\
6 & 0 & 0 & $1: 1,5$ & 4 & 100,00 & 41,27 & 72,79 & 81,73 \\
7 & 0 & 0 & $1: 1,5$ & 4 & 100,00 & 49,19 & 76,76 & 67,76 \\
8 & -1 & 0 & $1: 1$ & 4 & 100,00 & 44,27 & 83,16 & 49,30 \\
9 & +1 & 0 & $1: 2$ & 4 & 98,04 & 64,52 & 74,01 & 84,19 \\
10 & 0 & -1 & $1: 1,5$ & 2 & 96,94 & 58,41 & 61,02 & 75,45 \\
11 & 0 & +1 & $1: 1,5$ & 6 & 100,00 & 62,66 & 83,51 & 68,27 \\
\hline
\end{tabular}

A análise estatística para o tratamento da Amostra I mostrou que os efeitos significativos para a recuperação mássica de óleo refinado $\left(\mathrm{R}_{1}\right)$ estão relacionados às variáveis linear $(+17,94) \mathrm{e}$ quadrática $(-6,83)$ de concentração de água no solvente. $O$ fator linear proporção mássica de óleo:solvente também apresentou efeito significativo sobre essa variável resposta, sendo negativo $(-4,31)$. Deste modo, percebe-se que o aumento da porcentagem de água no solvente melhora a recuperação mássica de óleo refinado, assim como o decréscimo da proporção mássica óleo:solvente (Figura 1a). Para a remoção de ácidos graxos livres $\left(\mathrm{R}_{2}\right)$, as variáveis linear e quadrática de proporção mássica óleo:solvente apresentaram efeitos significativos positivo $(+22,73)$ e negativo $(-12,27)$ respectivamente, bem como a interação linear dessas duas variáveis $(+8,93)$. Essa análise indica que o aumento da proporção mássica óleo:solvente e da concentração de água no solvente (Figura 1b) contribui para a remoção de ácidos graxos livres $\left(\mathrm{R}_{2}\right)$.

Comportamento similar foi observado para a Amostra II (Figura 2a) com relação à recuperação mássica de óleo refinado $\left(\mathrm{R}_{1}\right)$. No entanto, para a maximização da remoção de ácidos graxos livres $\left(R_{2}\right)$ é necessário um aumento da proporção mássica óleo:solvente e redução da concentração de água no solvente (Figura 2b), visto que o fator linear proporção mássica de óleo:solvente e a interação com a concentração de água no solvente apresentaram efeito positivo $(+137,80$ e $+27,05$, respectivamente). Os fatores linear e quadrático da concentração de água no solvente e o fator quadrático da proporção mássica de óleo:solvente apresentaram efeito negativo sobre essa variável resposta, com respectivos valores $(-10,04),(-16,20)$ e $(-19,80)$.

Para a Amostra III, os efeitos que se apresentaram significativos na recuperação mássica de óleo refinado $\left(\mathrm{R}_{1}\right)$ foram as variáveis lineares de proporção mássica $(-4,38)$ e de porcentagem de água $(+8,59)$, assim como a interação linear entre elas $(-6,36)$ (Figura 3a). Para a remoção de ácidos graxos livres $\left(\mathrm{R}_{2}\right)$, o único fator que não foi significativo ao nível de confiança de $95 \%$ foi o quadrático da concentração de água no solvente (Figura 3b). Assim, a recuperação mássica é favorecida com a diminuição da razão mássica óleo:solvente e com o aumento da porcentagem de água no solvente, enquanto a remoção de ácidos graxos livres é favorecida nas condições inversas. 

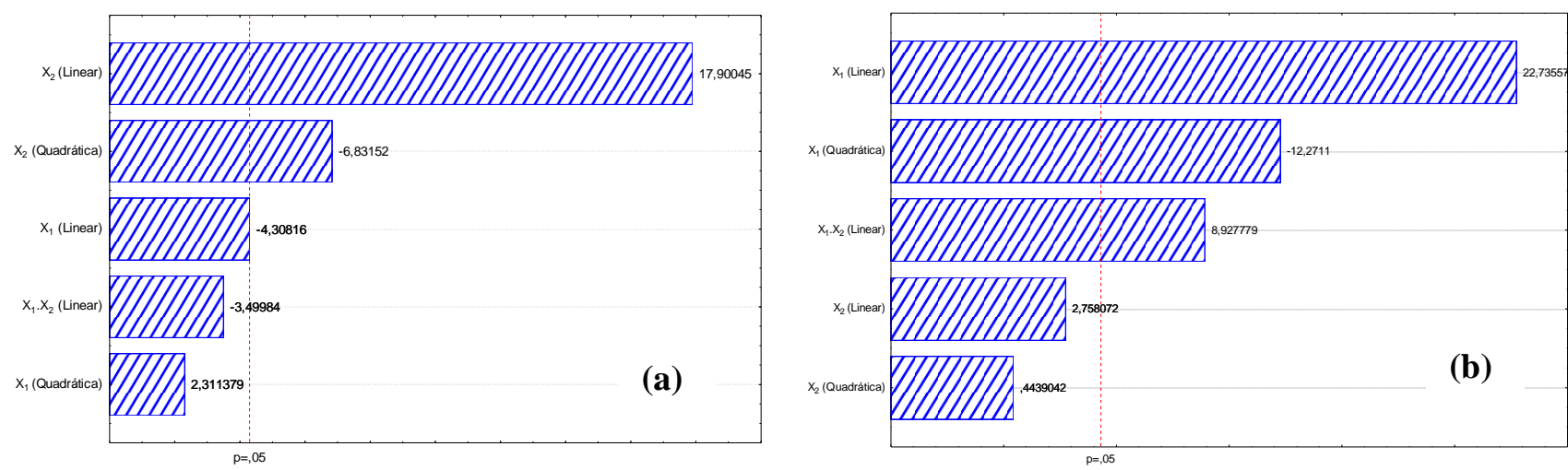

Figura 1 - Efeito das variáveis independentes estudadas $\left(\mathrm{X}_{1}=\right.$ proporção mássica de óleo:solvente e $\mathrm{X}_{2}=$ concentração de água no solvente) na EEL para a Amostra I sobre: a) Recuperação mássica de óleo neutro $\left(R_{1}\right)$ e b) Remoção de ácidos graxos livres $\left(R_{2}\right)$.
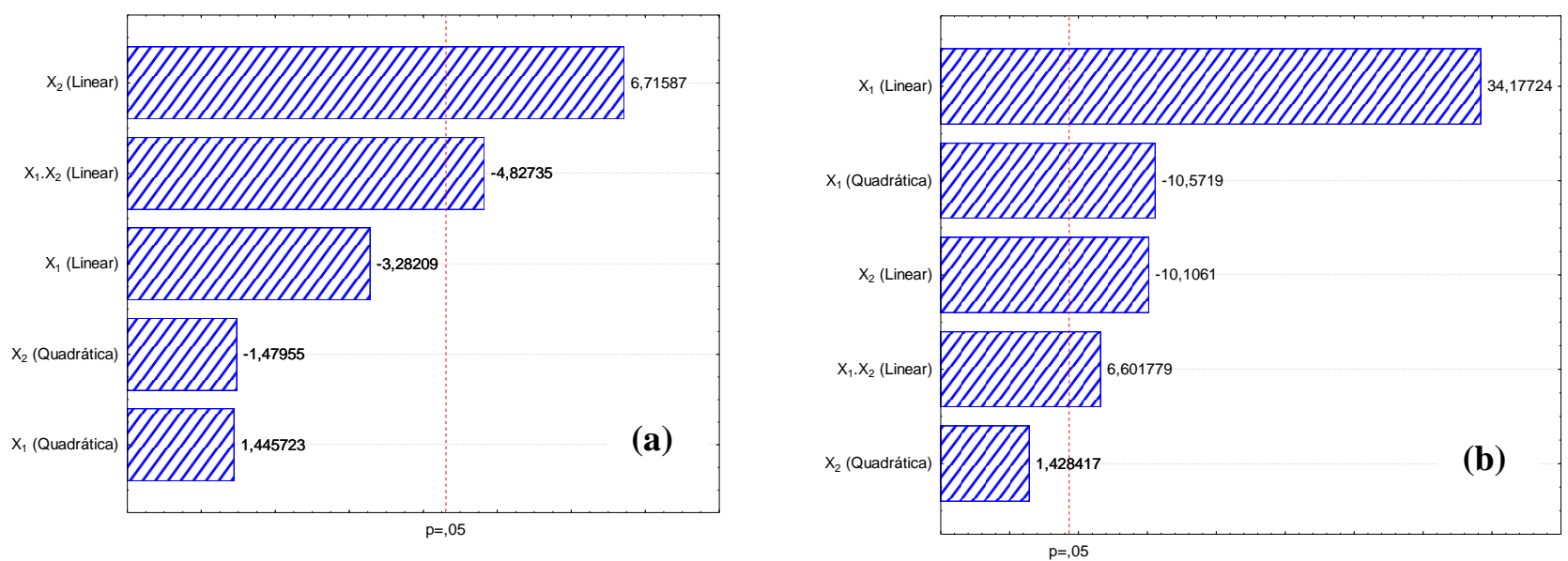

Figura 2 - Efeito das variáveis independentes estudadas $\left(\mathrm{X}_{1}=\right.$ proporção mássica de óleo:solvente e $\mathrm{X}_{2}=$ concentração de água no solvente) na EEL para a Amostra II sobre: a) Recuperação mássica de óleo neutro $\left(\mathrm{R}_{1}\right)$ e b) Remoção de ácidos graxos livres $\left(\mathrm{R}_{2}\right)$.
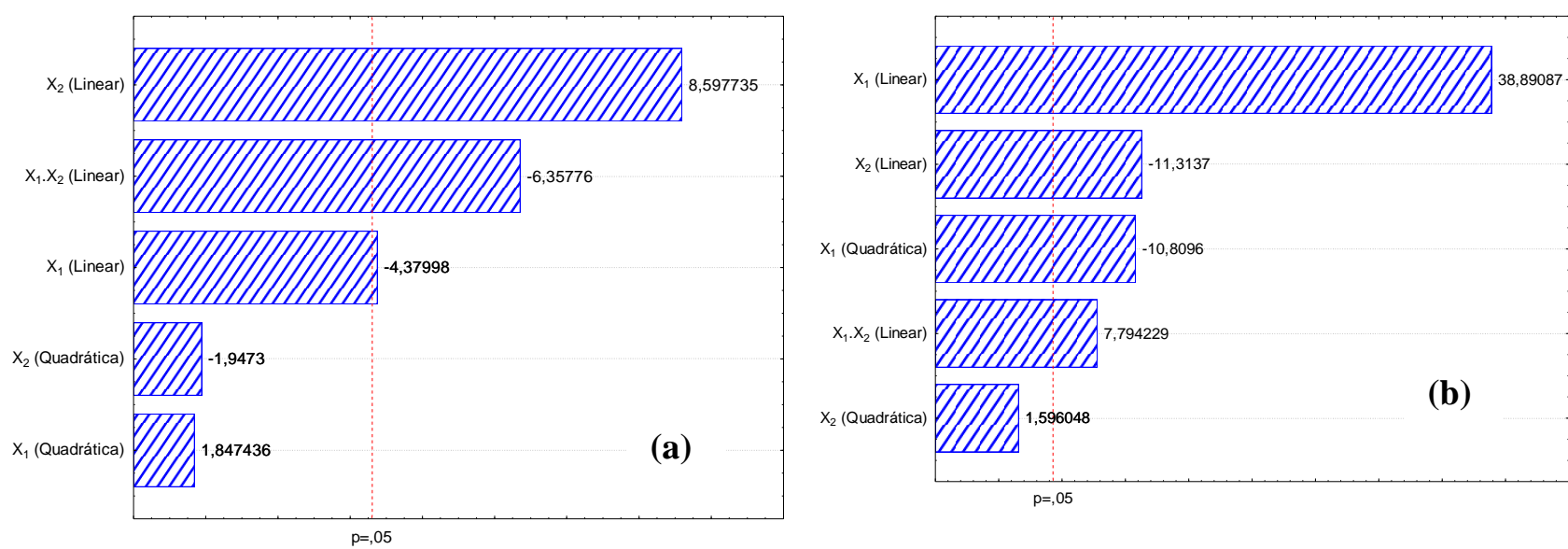

Figura 3 - Efeito das variáveis independentes estudadas $\left(\mathrm{X}_{1}=\right.$ proporção mássica de óleo:solvente e $\mathrm{X}_{2}=$ concentração de água no solvente) na EEL para a Amostra III sobre: a) Recuperação mássica de óleo neutro $\left(\mathrm{R}_{1}\right)$ e b) Remoção de ácidos graxos livres $\left(\mathrm{R}_{2}\right)$. 
As análises das variáveis respostas indicaram que as condições experimentais para otimizar tanto a porcentagem de recuperação mássica $\left(\mathrm{R}_{1}\right)$ como a porcentagem de remoção de ácidos graxos livres $\left(\mathrm{R}_{2}\right)$ não são coincidentes, ou seja, o aumento ou decréscimo do valor de um fator pode afetar positivamente uma variável resposta ou negativamente a outra. Assim, foi necessário encontrar um ponto ótimo em que as duas respostas não apresentassem perda considerável, sendo obtido a partir da sobreposição dos gráficos das curvas de nível pelo Design Expert 6.0 (Figura 4).

(a)

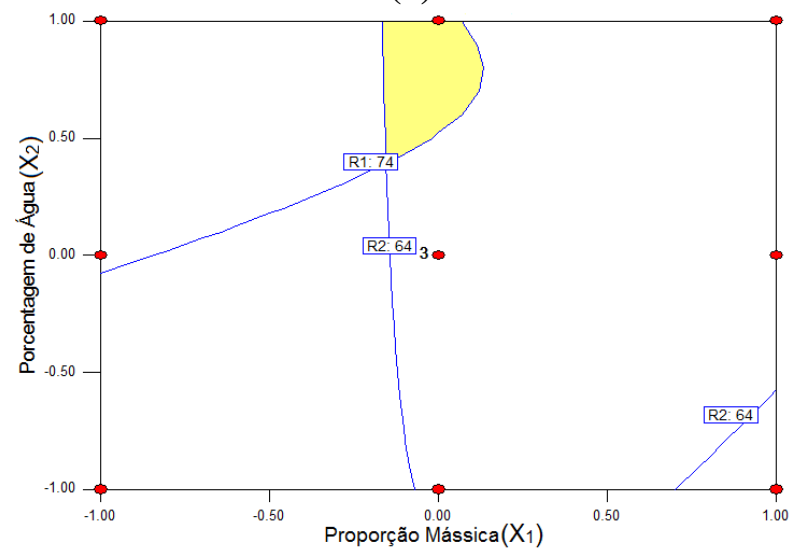

(b)

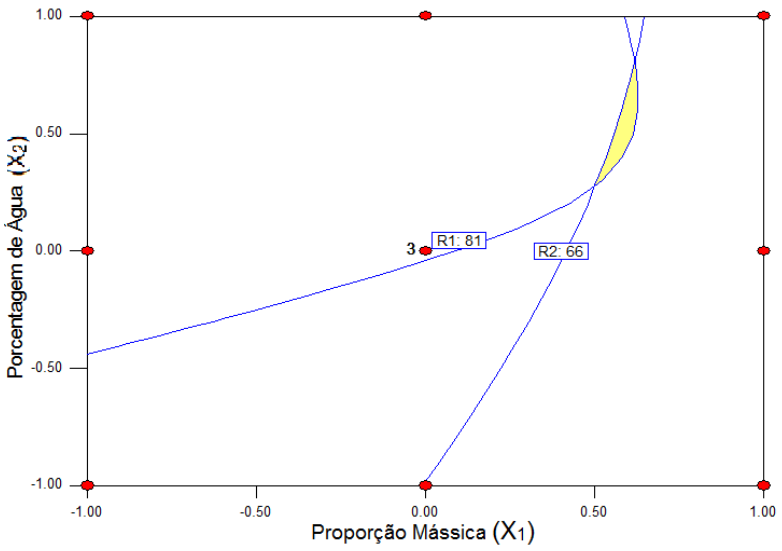

(c)

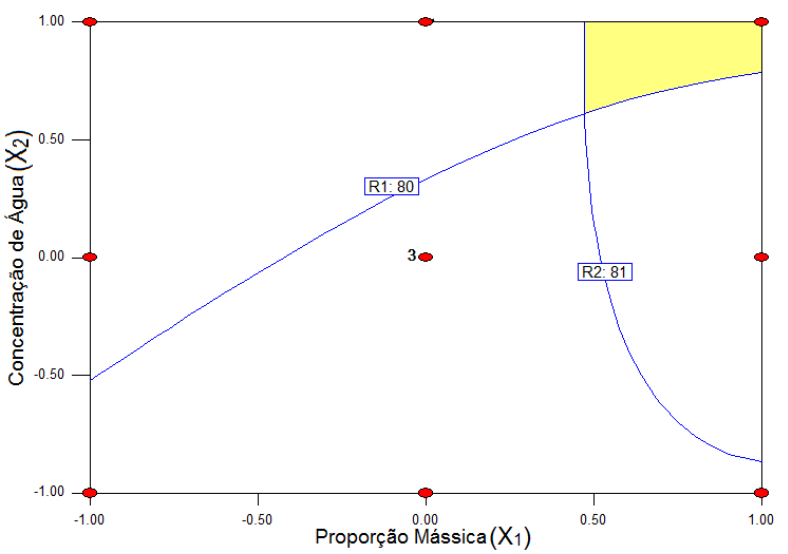

Figura 4 - Sobreposição de curvas de nível de valores codificados para recuperação mássica de óleo refinado $\left(\mathrm{R}_{1}\right)$ e remoção de ácidos graxos livres $\left(\mathrm{R}_{2}\right)$ com indicação do ponto ótimo dos fatores proporção mássica óleo:solvente $\left(\mathrm{X}_{1}\right)$ e concentração de água no solvente $\left(\mathrm{X}_{2}\right)$ obtidas para: a) Amostra $\left.\mathrm{I}, \mathrm{b}\right)$ Amostra II e c) Amostra III.

De maneira geral, pode-se concluir a partir da análise dos gráficos da Figura 4 que os maiores valores de recuperação mássica de óleo refinado $\left(\mathrm{R}_{1}\right)$ e remoção de ácidos graxos livres $\left(\mathrm{R}_{2}\right)$ podem ser encontrados, na região estudada, no nível alto de concentração de água no solvente $\left(\mathrm{X}_{2}\right)$ e entre o ponto central e o nível alto de proporção mássica de óleo:solvente $\left(\mathrm{X}_{1}\right)$.

Decodificando os valores obtidos a partir da sobreposição das curvas de nível, o ponto ótimo determinado para cada amostra de óleo, apresenta as seguintes condições: Amostra $\mathrm{I}, \mathrm{X}_{1}=1: 1,5 \mathrm{e}$ $\mathrm{X}_{2}=5,78 \%$, o que corresponde a $74 \%$ de $\mathrm{R}_{1}$ e $64 \%$ de $\mathrm{R}_{2}$; Amostra II, $\mathrm{X}_{1}=1: 1,6$ e $\mathrm{X}_{2}=5,80 \%$ o que corresponde a $81 \%$ de $\mathrm{R}_{1}$ e $66 \%$ de $\mathrm{R}_{2}$ e Amostra III, $\mathrm{X}_{1}=1: 1,9$ e $\mathrm{X}_{2}=5,90 \%$ o que corresponde a $80 \%$ de $\mathrm{R}_{1}$ e $81 \%$ de $\mathrm{R}_{2}$. 
Para confirmar a predição desses valores, experimentos adicionais foram realizados nas condições determinadas, sendo constatada a confiabilidade da análise estatística. Os resultados obtidos experimentalmente para a Amostra I, II e III, foram respectivamente: $72,41 \%$ de $\mathrm{R}_{1} \mathrm{e}$ $71,58 \%$ de $\mathrm{R}_{2} ; 84,59 \%$ de $\mathrm{R}_{1}$ e $62,81 \%$ de $\mathrm{R}_{2} ; 79,11 \%$ de $\mathrm{R}_{1}$ e $95,86 \%$ de $\mathrm{R}_{2}$.

\section{CONCLUSÃO}

Pode-se concluir que a utilização da técnica do planejamento de experimentos $\left(2^{2}\right.$ de face centrada) a partir de uma matriz empregando os fatores: porcentagem de água no solvente alcoólico e proporção mássica de óleo:solvente foi adequada para estudar a eficiência da desacidificação de amostras de óleo de coco com diferentes níveis de acidez por extração líquidolíquido, demonstrando valores elevados das variáveis respostas: porcentagem de recuperação mássica de óleo refinado e porcentagem de remoção de ácidos graxos livres, proporcionando um método alternativo ao refino alcalino convencional. Trabalhos futuros serão realizados em células de equilíbrio que além de permitirem um controle adequado da temperatura, favorecem o particionamento das fases no processo de extração, visando viabilizar a EEL, uma técnica ambientalmente favorável, para o refino de óleos vegetais.

\section{REFERÊNCIA BIBLIOGRÁFICA}

ANVISA - Agencia Nacional de Vigilancia Sanitaria. Resolucao ${ }^{\circ}$ 482, de 23 de setembro de 1999. Disponivel em: http://www.anvisa.gov.br/legis/resol/482_99.htm. Acesso em: 08 de jul. 2013.

AOCS. American Oil Chemists' Society Official Methods and Recommended Practices of the AOCS. 5th Ed. Champaign: AOCS Press, 2004. 1200p.

ATADASHI, I. M.; AROUA, M. K.; ABDUL-AZIZ, A. R.; SULAIMAN, N. M. N. Production of biodiesel using high free fatty acid feedstocks. Renew Sust. Energy Rev., v. 16, n. 5, p. 3275-3285, 2012.

BHOSLE, B. M.; SUBRAMANIAN, R. New approaches in deacidification of edible oils - a review. $J$. Food Eng., v. 69, n. 4, p. 481-494, 2005.

CERIANI, R.; MEIRELLES, A. J. A. Simulation of continuous physical refiners for edible oil deacidification. J. Food Eng., v. 76, n. 3, p. 261-271, 2006.

MOUSTAFA, A.; STAUFFER, C. Bakery fats. Brussels: American Soybean Association, 1997. Disponível em: 〈http://www.asaim-europe.org/Library/library_e.htm>, acessado em 15 de maio de 2006.

RIBEIRO, E. P.; SERAVALli, E. A.G. Química de Alimentos $2^{\mathrm{a}}$ ed. São Paulo: Edgard Blücher: 2007.

REZENDE-RIBEIRO, J. Desacidificação de óleo de macaúba por extração líquido-líquido para produção de biodiesel. Dissertação de Mestrado. Universidade Estadual do Sudoeste da Bahia. Itapetinga, 2009. 61p. 